\title{
EFEK EDUKASI "PAKET HARMONIS" TERHADAP PENGELOLAAN DIRI PEREMPUAN MENOPAUSE DALAM MENGATASI PERUBAHAN MASA MENOPOUSE
}

\author{
P-ISSN: 2089-4341 | E-ISSN: 2655-9633 \\ Link: https://uia.e-journal.id/akademika/article/view/667 \\ DOI: $\underline{10.34005 / a k a d e m i k a . v 9 i 01.667}$ \\ Marini Agustin, \\ marinidilla@gmail.com \\ Universitas Muhammadiyah Jakarta, \\ Universitas Islam As-Syafi'iyah Jakarta \\ Ima Nursanti \\ imanursantifik@gmail.com \\ Universitas Muhammadiyah Jakarta
}

\begin{abstract}
ABSTRAK : Menopause merupakan suatu fase yang akan dialami oleh setiap perempuan yang biasanya terjadi diatas umur 40 tahun. Perempuan dikatakan menopause bila siklus menstruasinya telah berhenti selama 1 tahun. Tujuan dari penelitian ini adalah untuk mengetahui Efek Paket Harmonis terhadap pengelolaan diri perempuan menopause dalam mengatasi perubahan masa menopause di kota bogor. Penelitian ini merupakan penelitian kuantitatif dengan metode quasi experiment dengan menggunakan pendekatan pre-post test with control. Pengumpulan data dilakukan secara kuantitatif. Besar sampel 60 responden, yang terdiri dari 30 kelompok intervensi dan 30 kelompok kontrol, yang diambil dengan teknik purposive sampling. Hasil analisis bivariat pada pengelolaan diri (pemantauan diri, pengendalian diri, penghargaan diri) didapatkan $\mathrm{P}$ Value $=0,0000(\mathrm{P}$ Value $<\alpha=0,005)$, hasil ini membuktikan bahwa "Paket Harmonis" berpengaruh pada peningkatan pengelolaan diri perempuan menopause kelompok intervensi dalam mengatasi permasalahan masa menopause. Pada kelompok kontrol tidak menunjukkan perubahan yang bermakna dalam pengelolaan diri perempuan menopause, didapatkan nilai pemantauan diri $\mathrm{p}$ Value $=0,234$, pengendalian diri $\mathrm{p}$ Value $=0,848$ dan penghargaan diri $\mathrm{p}$ Value $=0,095$ dapat disimpulkan pada kelompok kontrol nilai $\mathrm{p}$ Value $>0.05$ artinya tidak ada perbedaan yang bermakna pada kelompok kontrol. Saran dari peneliti agar penelitian ini dapat dijadikan data dasar untuk dilakukan penelitian lebih lanjut agar dapat memberikan manfaat bagi perempuan menopause.
\end{abstract}

Kata kunci: Paket harmonis; pengelolan diri perempuan menopause memberikan manfaat yang lebih besar pada perempuan menopause.

ABSTRACT : Menopause is a phase that will be experienced by every woman who usually occurs above the age of 40 years. Women are said to be menopausal if their menstrual cycles have stopped for 1 year. The purpose of this study was to determine the effect of Harmonious Packages on the self-management of menopausal women in overcoming changes in menopause in Bogor City. This research is a quantitative study with a quasi-experimental method using a pre-post test with control approach. Data collection is done quantitatively. Large sample of 60 respondents, consisting of 30 intervention groups and 30 control groups, which were taken by purposive sampling technique. The results of bivariate analysis on self-management (self-monitoring, selfcontrol, self-esteem) obtained $P$ Value $=0.0000$ ( $P$ Value $<\alpha=0.005)$, these results prove that the "Harmonious Package" effect on improving the self-management of menopausal women in the intervention group in Overcoming the problems of menopause. In the control group did not show a significant change in self-management of menopausal women, obtained self-monitoring value $p$ Value $=0.234$, self-control $p$ Value $=0.848$ and self-esteem $p$ Value $=0.095$ can be concluded in the control group the value of $p$ Value $>0.05$ means that there is no difference which was significant in the control group. Suggestions from researchers so that this study can be used as basic data for further research in order to provide greater benefits to menopausal women. 


\section{PENDAHULUAN}

Keberhasilan pembangunan dibidang kesehatan menyebabkan terjadinya peningkatan Umur Harapan Hidup (UHH). Berdasarkan laporan Badan Pusat Statistik (BPS) 2017 UHH penduduk Indonesia adalah 73,06 dan dipredikasi akan naik sekitar 73,7 tahun pada periode 2020-2025, dengan perkiraan jumlah penduduk Indonesia akan mencapai 273,65 juta jiwa pada tahun 2025. Seiring dengan meningkatnya UHH semakin bertambah pula jumlah perempuan menopause yang merupakan bagian dari cakupan kesehatan perempuan di Indonesia.

WHO (World Health Organization) memperkirakan UHH hidup orang Indonesia adalah 75 tahun pada tahun 2025. Hal ini berarti perempuan memiliki kesempatan untuk hidup rata-rata 25 tahun lagi sejak awal menopause. Menurut Badan Pusat Statistik (BPS) Kota Bogor pada tahun 2017 didapatkan data jumlah penduduk perempuan dengan usia diatas 45 tahun sebanyak 129.092 dari 532.813 atau sekitar $24,2 \%$ dari total jumlah penduduk.

Menopause merupakan suatu fase yang akan dialami oleh setiap perempuan yang biasanya terjadi diatas umur 40 tahun. Perempuan dikatakan menopause bila siklus menstruasinya telah berhenti selama 1 tahun. Berhentinya haid tersebut akan membawa dampak pada kesehatan baik fisik maupun psikis. Sebagian Faktor yang mempengaruhi terhadap gejala menopause antara lain faktor psikis yaitu perubahan-perubahan psikologis maupun fisik yang berhubungan dengan kadar estrogen, gejala yang menonjol adalah berkurangnya tenaga dan gairah, berkurangnya konsentrasi dan kemampuan akademik, timbulnya perubahan emosi seperti tersinggung, susah tidur, rasa kekurangan, rasa sepi, ketakutan, tidak sabar dan lain-lain. Perubahan ini berbeda-beda tergantung dari kemampuan perempuan untuk menyesuaikan diri (Proverawati, 2010). Perempuan menopause 
perlu melakukan adaptasi terhadap perubahan-perubahan tersebut agar bisa mengatasi permasalahan yang mereka alami.

Proses adaptasi perempuan menopause tersebut dapat diintegrasikan dengan teori model keperawatan menurut Sister Calista Roy yang mengemukakan bahwa manusia sebagai makhluk biopsikososial yang berinteraksi terus menerus dan dipengaruhi oleh perubahan lingkungan. Lingkungan ini mencakup stimulus fokal, stimulus kontekstual dan stimulus residual. Setiap orang memahami bagaimana individu mempunyai batas kemampuan untuk beradaptasi. Pada dasarnya manusia memberikan respon terhadap semua rangsangan baik positif maupunnegatif.(Tomey,A\&Alligood,2010).

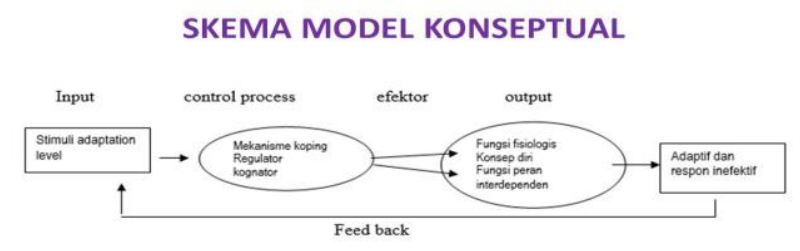

Gambar 1.Skema Model Konseptual

Penelitian tentang menopause yang dilakukan pada perempuan Makedonia oleh Strezova, Anita dkk, (2017) perempuan menopause kekurangan informasi dan kurang mengetahui tentang menopause dan pria Makedonia cenderung menganggap istri mereka berbeda setelah menopause. Perempuan menganggap perubahan dalam sikap pria ini sebagai faktor pemicu dalam kekerasan dalam rumah tangga, urusan di luar nikah, dan perceraian.

Penelitian yang dilakukan oleh Atikah (2016) tentang pengaruh pendidikan kesehatan terhadap kesiapan menghadapi menopause di Sleman Yogyakarta didapatkan hasil perempuan pre menopause sebelum dilakukan penyuluhan kesehatan sebagian besar dalam kategori tidak siap menghadapi menopause yaitu $53,3 \%$. Sesudah dilakukan penyuluhan kesehatan sebagian besar responden dalam kategori siap menghadapi menopause yaitu 80,0\%.

Berdasarkan studi pendahuluan dengan melakukan wawancara di Puskesmas Tanah sereal, Kota Bogor, Jawa Barat, dari 10 perempuan menopause yang diwawancara 8 perempuan memiliki kesulitan mengatasi perubahan yang terjadi 
pada masa menopause seperti rasa panas, insomnia, nyeri tulang, mudah marah, sakit saat berhubungan seksual dan keluhan lainnya. Hal ini disebabkan kurangnya pengetahuan tentang menopause dan gejala-gejala yang menyertai, serta tidak mengetahuI penyebab keluhan-keluhan yang mereka alami.

Upaya meningkatkan pengetahuan pada perempuan menopause dapat diwujudkan dengan intervensi keperawatan melalui pendidikan kesehatan, sebagai sarana untuk memberikan pemahaman pada perempuan menopause mengenai informasi yang bersifat positif sehingga akan diikuti perubahan perilaku yang positif. Intervensi menopause diberikan dalam bentuk pemberian informasi seperti adanya perubahan-perubahan pada tubuh yang terjadi karena disebabkan menurunnya hormon estrogen pada perempuan menopause dan bagaimana melakukan pengelolaan diri terhadap perubahan masa menopause tersebut. Ketika perempuan paham akan perubahan dan bisa melakukan pengeloaan dirinya, hal ini akan mampu merubah cara pandang dan perilakunya menjadi lebih baik.

Peran perawat sebagai pendidik sangat dibutuhkan perempuan menopause dalam mengelola permasalahan masa menopause, untuk itu profesi keperawatan memiliki kesempatan dalam memberikan pelayanan kesehatan berupa tindakan dan program pendidikan kesehatan perempuan menopause dengan memberikan informasi tentang kemampuan perempuan menopause dalam mengelola permasalahan masa menopause.

Pemberian intervensi keperawatan dikemas dalam bentuk "paket harmonis". Pemberian paket harmonis ini bertujuan untuk meningkatkan pengetahuan dan pengelolaan diri perempuan menopause dalam mengatasi perubahan masa menopause sehingga mereka memiliki kemampuan menjalani proses menua dengan sehat dan bahagia. Dengan pemberian Paket harmonis dapat terjadi perubahan perilaku perempuan menopause sehingga mampu melakukan pengelolaan diri dengan baik.

\section{METODE}

\section{Desain}


Penelitian ini merupakan penelitian kuantitatif dengan metode quasi experiment dengan menggunakan pendekatan pre-post test with control pada kelompok intervensi dan kelompok kontrol. Penelitian ini mengukur Efek Edukasi Paket "Harmonis" Terhadap Pengelolaan Diri Perempuan Menopause Dalam Mengatasi Perubahan Masa Menopause.

\section{Sampel}

Berdasarkan hasil perhitungan, didapatkan jumlah sampel yang diperlukan dalam penelitian pada masing-masing kelompok intervensi dan kelompok kontrol adalah sebesar 30 responden yang memenuhi kriteria inklusi dan eksklusi sehingga jumlah total sampel adalah 60 responden.

\section{Etika Penelitian}

Penelitian ini dilakukan setelah mendapatkan lolos kaji etik di universitas Muhammadiyah Jakarta. Peneliti sudah menjelaskan tujuan, metode dan manfaat penelitian kepada responden serta menjaga kerahasian identitasnya.

\section{Analisis Statistik}

Analisis statistik dilakukan untuk mengetahui gambaran karakteristik dan pengelolaan diri perempuan menopause. uji t-test berpasangan dilakukan untuk mengetahui ada tidaknya perbedaan pada kelompok kontrol dan intervensi yang diberikan paket harmonis.

\section{HASIL}

\section{Analisis Univariat}

Hasil penelitian, dari 30 responden kelompok intervensi usia rata-rata adalah 52.53, sedangkan dari 30 responden kelompok kontrol usia rata-rata adalah 52.43. Semua responden kelompok intervensi dan kontrol beragama islam dan tidak bekerja (ibu rumah tangga).

Tingkat Pendidikan terbanyak adalah pendidikan rendah, pada kelompok intervensi 56.7\% dan kelompok kontrol sebanyak 60 \%. Suku Sunda merupakan suku yang terbanyak yaitu pada kelompok intervensi $86,7 \%$ dan pada kelompok kontrol 80\%. Dari hasil uji homogenitas kedua kelompok dinyatakan homogen dimana didapatkan nilai $p$ value $>0,05$.

\section{Tabel 1.}


Distribusi Responden Berdasarkan Karakteristik Perempuan Menopause Di Kota Bogor

\begin{tabular}{|c|c|c|c|c|c|c|}
\hline \multirow{2}{*}{ Variabel } & \multirow{2}{*}{ Deskripsi } & \multicolumn{2}{|c|}{$\begin{array}{c}\text { Intervensi } \\
\mathbf{n}=\mathbf{3 0}\end{array}$} & \multicolumn{2}{|c|}{$\begin{array}{c}\begin{array}{c}\text { Kontrol } \\
\mathbf{n}=\mathbf{3 0}\end{array} \\
\end{array}$} & \multirow{2}{*}{$\begin{array}{c}\text { p Value } \\
\text { Uji } \\
\text { Homogenitas }\end{array}$} \\
\hline & & $\begin{array}{c}\text { Sebelum } \\
\text { F }\end{array}$ & $\begin{array}{c}\text { Setelah } \\
\%\end{array}$ & $\begin{array}{c}\text { Sebelum } \\
\text { F }\end{array}$ & $\begin{array}{c}\text { Setelah } \\
\%\end{array}$ & \\
\hline \multirow[t]{5}{*}{ Usia } & Mean & 52.53 & & 52.43 & & \\
\hline & Modus & 49 & & 52 & & \\
\hline & Median & 52.50 & & 52.00 & & 0.106 \\
\hline & SD & 3.014 & & 2.417 & & \\
\hline & Min-max & $48-57$ & & $49-57$ & & \\
\hline \multirow[t]{2}{*}{ Agama } & Non Muslim & 0 & 0 & 0 & 0 & - \\
\hline & Muslim & 30 & 100 & 30 & 100 & \\
\hline \multirow[t]{2}{*}{ Pendidikan } & Rendah & 17 & 56.7 & 18 & 60 & 0,615 \\
\hline & Tinggi & 13 & 43.3 & 12 & 40 & \\
\hline \multirow[t]{2}{*}{ Pekerjaan } & Tidak bekerja & 30 & 100 & 30 & 100 & - \\
\hline & Bekerja & 0 & 0 & 0 & 0 & \\
\hline \multirow[t]{2}{*}{ Suku } & Non Sunda & 4 & 13.3 & 6 & 20 & 0,172 \\
\hline & Sunda & 26 & 86.7 & 24 & 80 & \\
\hline \multicolumn{7}{|l|}{$\begin{array}{c}\text { Pengelolaan } \\
\text { Diri }\end{array}$} \\
\hline Pamantauan & Tidak Mampu & 19 & 0 & 11 & 14 & 0,610 \\
\hline diri & Mampu & 11 & 30 & 19 & 16 & \\
\hline Pengendalian & Tidak Mampu & 17 & 0 & 16 & 17 & 0,533 \\
\hline diri & Mampu & 13 & 30 & 14 & 13 & \\
\hline Penghargaan & Tidak Mampu & 15 & 0 & 18 & 15 & 0,377 \\
\hline diri & Mampu & 15 & 30 & 12 & 15 & \\
\hline
\end{tabular}

\section{Analisis Bivariat}

Tabel 2 :

Perbedaan Rata-Rata Pengelolaan Diri Perempuan Menopause Sebelum Dan Sesudah Diberikan "Paket Harmonis"

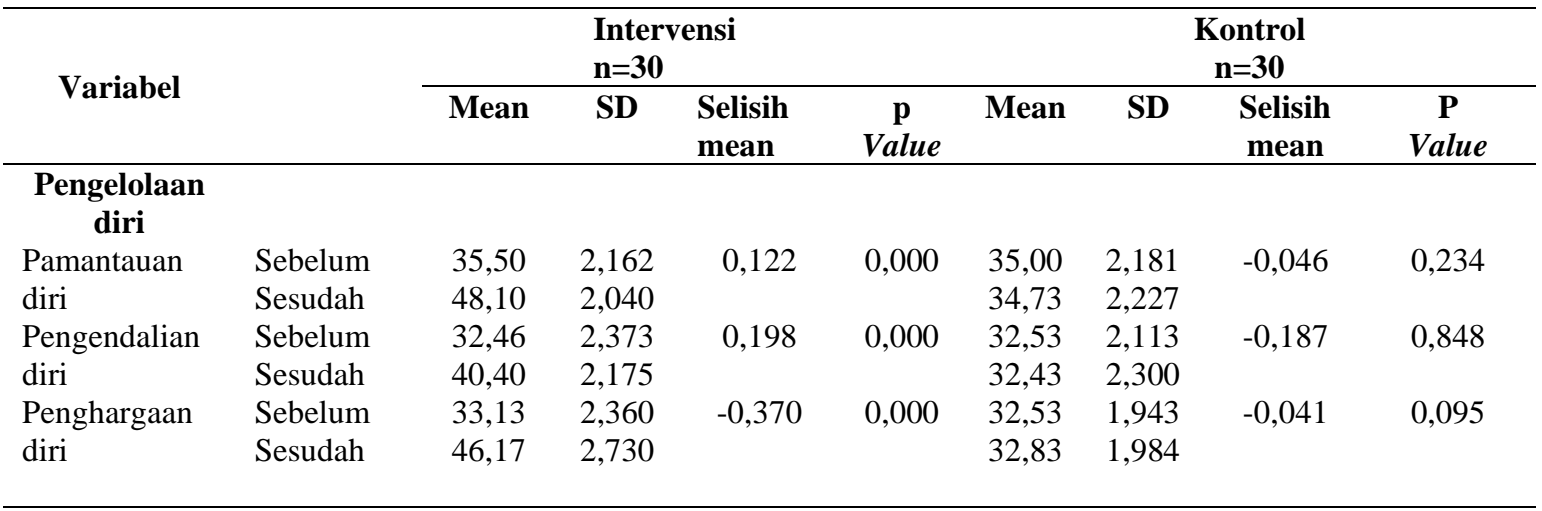

Berdasarkan hasil analisis data pada tabel 5.3 diketahui bahwa pada kelompok intervensi sesudah diberikan "Paket Harmonis" berpengaruh secara bermakna dibanding kelompok kontrol yang tidak diberikan paket, didapatkan hasil analisis pemantauan diri, pengendalian diri dan penghargaan diri dengan $p$ value $=0.000$. Sehingga hipotesa gagal ditolak karena $p<0,05$, hasil ini membuktikan bahwa "Paket Harmonis" berpengaruh pada peningkatan pengelolaan diri perempuan menopause kelompok intervensi dalam mengatasi permasalahan masa menopause. 
Pada kelompok kontrol tidak menunjukkan perubahan yang bermakna dalam pengelolaan diri perempuan menopause, didapatkan nilai pemantauan diri p Value $=0,234$, pengendalian diri $\mathrm{p}$ Value $=0,848$ dan penghargaan diri $\mathrm{p}$ Value $=0,095$ dapat disimpulkan pada kelompok kontrol nilai p Value $>0.05$ artinya tidak ada perbedaan yang signifikan nilai rata-rata pada kelompok kontrol, dengan demikian hipotesis nol diterima.

\section{PEMBAHASAN}

Gambaran Usia responden, usia rata-rata responden pada penelitian ini, baik pada kelompok intervensi dan kelompok kontrol adalah 52 tahun. Hal ini sesuai dengan pendapat Ratna (2014) bahwa usia perempuan menopause terbanyak adalah umur 45-54 tahun dengan usia rata-rata 50 tahun. Menurut Prawirihardjo (2008) menopause mulai pada usia 50-51 tahun. Beberapa faktor yang mempengaruhi usia menopause adalah usia menarche, menurut Speroff dan Reitz (2010), wanita yang terlambat mendapatkan menstruasi, pada usia 16 atau 17 tahun, justru akan mengalami menopause lebih cepat, sedangkan mereka yang haid lebih dini seringkali akan mengalaminya sampai pada usia mencapai 50 tahun. Ada pola keluarga yang berlaku secara umum, bagi seorang wanita yang ibu atau kakak perempuannya lebih dini mengalami menopause maka ia juga cenderung mengalami hal yang sama, begitu pula sebaliknya. Menurut washington, T.R (2013) semakin meningkat usia semakin baik manajemen diri (pengelolaan diri) seseorang.

Status pendidikan juga dapat menjadi faktor yang berhubungan dengan menopause. Schoenaker menyatakan bahwa wanita yang memiliki status pendidikan tinggi dan menengah akan memasuki masa menopause lebih lambat dibandingkan dengan wanita yang memiliki pendidikan yang rendah (Schoenaker dkk., 2014). Hal tersebut dapat terjadi dikarenakan tingkat pendidikan merupakan salah satu dari faktor sosial ekonomi yang dapat berpengaruh terhadap usia menopause melalui pola dan kualitas dari pola makan, paritas dan IMT, namun pengaruh secara pasti dari tingkat pendidikan masih belum terlalu jelas (Tehrani dkk., 2014).

Hasil penelitian menunjukkan tingkat pendidikan yang paling banyak pada kedua kelompok intervensi dan kontrol adalah pendidikan rendah, tetapi bukan berarti seseorang yang memiliki pendidikan rendah mutlak berpengetahuan rendah pula, mengingat bahwa peningkatan pengetahuan tidak selalu dari pendidikan formal akan tetapi juga bisa dari pendidikan non formal. (Wawan. A, 2010).

Dapat dibuktikan dengan adanya pengaruh "Paket Harmonis" yang signifikan pada kelompok intervensi setelah dilakukan perlakuan melalui pendidikan kesehatan dan 
pemberian booklet walaupun rata-rata mereka berpendidikan rendah. Sehingga diharapkan mereka mampu melakukan pengelolaan diri dalam mengatasi perubahan masa menoapuse.

Hasil Penelitian menunjukkan pekerjaan semua responden pada kelompok intervensi dan kontrol adalah ibu rumah tangga (tidak bekerja), menurut penelitian yang dilakukan oleh Lilik P (2015) terdapat hubungan pekerjaan dengan adaptasi menopause pada perempuan, dimana perempuan bekerja memiliki adaptasi yang lebih ringan dibanding dengan perempuan tidak bekerja, hal ini dimungkinkan karena ibu tidak bekerja lebih sulit atau sedikit medapatkan informasi mengenai gejala dan masalah yang dihadapi pada masa menopause. Menurut Kasdu (2004) seseorang yang menjalani masa menopause membutuhkan informasi yang benar tentang menopause yang akan membantu mereka dalam memahami dan mempersiapkan dirinya menjalani menopause dengan baik.

Berdasarkan hasil penelitain seluruh responden beragama islam baik pada kelompok intervensi dan kelompok kontrol. Sebagian perempuan memandang menopause sebagai hal yang alamiah/sunatullah bahkan disyukuri sebagai kenikmatan dari allah sehingga seseorang akan menghadapinya dengan penuh penerimaan dan keikhlasan sehingga berbagai gangguan fisiologis yang dialaminya tidak berdampak pada gangguan psikologis (Retnowati 2001).

Menurut Meithya, dkk (2012) tingkat religiusitas yang tinggi dapat membantu perempuan menghadapi menopause dan menjalani kehidupan paska menopause dengan lancar karena menurut mereka ibadah shalat dan puasa lebih lancar dibanding saat masih menstruasi.

Hasil penelitian menunjukkan sebagian besar responden memiliki suku Sunda, baik pada kelompok intervensi dan kelompok kontrol. Menopause merupakan peristiwa alami yang terjadi pada setiap wanita. Peristiwa alami tersebut dipengaruhi konteks budaya yang berbeda dan persepsi individual. Pada masyarakat pada umumnya, usia dewasa memiliki penghargaan yang tinggi dibandingkan usia lanjut, khususnya wanita yang memiliki keyakinan dalam diri bahwa sebagai wanita sudah merasa tidak sempurna, dengan berakhirnya proses menstruasi dan merasa tidak subur lagi. Perempuan mengalami perasaan-perasaan negatif saat mengalami menopause. Perasaan negatif yang menyertai adalah tidak cantik lagi, tidak berharga, tidak dibutuhkan.

Menurut Lisy S (2016) penerimaan terhadap peristiwa menopause merupakan hasil dari proses pengenalan dan penyesuaian diri dengan tradisi dan adat istiadat budaya di lingkungan. Pandangan budaya dan individual mempengaruhi persepsi wanita berhubungan dengan proses menopause dan gejala yang ditimbulkan dari menopause. (Kusmiran, 2011).

Hasil penelitian membuktikan bahwa ada efek paket harmonis setelah dilakukan intervensi, hal ini terlihat dari data hasil penelitian yang menunjukkan bahwa responden 
kelompok intervensi mengalami peningkatan terhadap pengelolaan diri (self management) karena mereka dapat mengelola dirinya dengan baik dalam menjalani masa menopause dibandingkan kelompok control.

Hasil penelitian juga membuktikan bahwa "Paket Harmonis" pada perempuan menopause dapat meningkatkan pengetahuan dan pemahaman serta merubah sikap dan kesadaran diri perempuan menopause sehingga mampu melakukan pemantauan diri (self monitoring), pengendalian diri (self controlling) dan penghargaan diri (self reward) guna meningkatkan persepsi dan kemampuan dalam mengatasi permasalahan pada masa menopause.

Thorne (2006) mendefinisikan pengelolaan diri (self management) sebagai kemampuan dan proses yang digunakan individu dalam upaya sadar dapat melakukan pengelolaan terhadap suatu kondisi dimana tubuh mengalami suatu perubahan baik fisik dan psikologis yang dapat menimbulkan suatu kondisi sakit. Self mangement merupakan bagian dari perawatan diri dimana hasil yang diperoleh dari penerapan program self management adalah perubahan perilaku terhadap kesehatan, kemampuan mengatasi permasalahan dan self efficacy (Wilkinson \& Whitehead, 2009).Perubahan perilaku kesehatan dapat dilakukan melalui pemantauan diri (self monitoring), pengendalian diri (self controlling), dan penghargaan diri (self reward) (Schilling et al, 2009).

Menurut Nursanti, I (2015) melalui penelitian tentang efek paket kemilau senja, terbukti berhasil membantu perempuan menopause dalam mengatasi permasalahan fisik, seksual dan psikologis masa menopause. Keberhasilan ini memberikan dampak positif bagi perempuan menopause untuk secara terus menerus melakukan tindakan perbaikan dengan melakukan keterampilan self management dalam mengatasi permasalahan masa menopause.

Paket Harmonis berbentuk pendidikan kesehatan dengan menggunakan metode pembelajaran, seperti: ceramah, diskusi, demonstrasi dan redemonstrasi terbukti mampu meningkatkan kemampuan pengelolaan diri perempuan menopause. Sesuai dengan teori bahwa pendidikan kesehatan merupakan suatu upaya untuk menciptakan pengetahuan dan perilaku masyarakat yang kondusif untuk kesehatan. pendidikan kesehatan kesehatan berupaya agar masyarakat menyadari atau mengetahui bagaimana cara memelihara kesehatan mereka, bagaimana menghindari atau mencegah hal-hal yang merugikan kesehatan mereka dan kesehatan orang lain, kemana seharusnya mencari pengobatan bilamana sakit, dan sebagainya. Pendidikan kesehatan pada akhirnya mencapai pengetahuan tentang kesehatan dan berlanjut perilaku kesehatan (Notoadmojo, 2012).

Integrasi model keperawatan Calista Roy pada perempuan menopause menitik beratkan pada kemampuan perempuan menopause dalam melakukan adaptasi terhadap stimulus fokal, stimulus kontekstual dan stimulus residual melalui proses kontrol dalam 
bentuk mekanisme koping yang di gunakan. Mekanisme kontrol ini dibagi atas subsistem regulator dan kognator. Respon subsistem tersebut dapat terlihat pada perubahan yang ada pada perempuan menopause yaitu fungsi fisiologis berupa perubahan fisik dan seksual, konsep diri dengan beradaptasi diberikan paket harmonis mampu mencapai tingkat adaptasi yang adaptif terhadap perubahan masa menopause dengan melakukan keterampilan pengelolaan diri berupa pemantauan diri, pengelolaan diri dan penghargaan diri.

Dari Hasil penelitian diatas dapat disimpulkan, terdapat perbedaan rata-rata pada kelompok intervensi sesudah diberikan "Paket Harmonis" dibandingkan dengan kelompok kontrol yang tidak diberikan paket, hasil ini membuktikan bahwa "Paket Harmonis" berpengaruh pada peningkatan pengelolaan diri perempuan menopause kelompok intervensi dalam mengatasi permasalahan masa menopause. Pada kelompok kontrol tidak menunjukkan perubahan yang bermakna dalam pengelolaan diri perempuan menopause.

Rekomendasi bagi pelayanan kesehatan agar paket harmonis ini dapat dijadikan sebagai sebagai salah satu intervensi keperawatan pada perempuan menopause, dan dapat menggunakan booklet paket harmonis dalam melakukan tindakan perawatan pada perempuan menopause.

\section{DAFTAR PUSTAKA}

Atikah, sri. (2016). Pengaruh Pendidikan Kesehatan Terhadap Kesiapan Menghadapi Menopause pada Ibu Premenopause di Dusun Klawisan Margoagung Sleman Yogyakarta. E-Journal UNISA.

Badan pusat statistic. (2017). Data Statistic Indonesia. http://www.datastatistikindonesia.com diakses tanggal 8 Januari 2019

Badan Pusat Statistic Kota Bogor. (2017). Data Statistic Kota Bogor. http://www.datastatistik Kota Bogor.com diakses tanggal 8 Januari 2019

Baziad, Ali. (2010). Menopause dan Andropause. Jakarta: Yayasan Bina Pustaka Sarwono Prawirorahardjo

Bener A, (2014). Measurementspecific Quality-Of-Life Satisfaction During Premenopause, Perimenopause And Postmenopause In Arabian Qatari Women. Journal of Mid-life Health. 5(3).

Dahlan,Sopiyudin,2014. Statistik Untuk Kedokteran Dan Kesehatan Edisi 6. Jakarta, Salemba Medika

Hidayat,. Aziz Alimul Henry. (2017). Metodologi Penelitian Keperawatan dan kesehatan. Jakarta: Salemba Medika.

Kasdu, (2004). Kiat Sehat dan Bahagia di Usia Menopause. Puspaswara. Jakarta: Gramedia Kementerian Kesehatan Republik Indonesia. (2017). Profil Kesehatan Indonesia 2017. Jakarta: Kementerian Kesehatan RI

Kusmiran, Eni. (2011). Kesehatan Reproduksi Remaja dan Wanita. Jakarta: Salemba Medika

Lowdermilk, D. L., \& Perry, S.E. (2012). Maternity and Women's Health Care. $8^{\text {th }}$ ed. St Louis, MO: Mosby. 
Mansour, Fakih. (2005). Analisis Gender dan Transformasi Sosial. Yogyakarta: Pustaka Pelajar

Mulyani, S. (2013). Menopause Akhir Siklus Menstruasi pada Wanita di

Notoatmodjo. (2010). Metodologi Penelitian Kesehatan. Jakarta : PT. Rineka Cipta

Nursanti, Irna (2015). Pengembangan "Paket Kemilau Senja" Dan Pengaruhnya Terhadap Pemahaman Serta Kemampuan Mengatasi Permasalahan Perempuan Menopause Di Jakarta Timur . Uiupdate. Ui.ac.id

Proverawati, A., dan Sulistyawati, Emi. (2010). Menopouse dan Sindrom Premenopause. Yogyakarta: Numed.

Ratna,Dewi.,(2014).3 Fase Penting Pada Wanita (Menarche, Menstruasi, Menopause) Jakarta: Gramedia

Schoenaker, Danielle AJM. (2014). Socio Economic Position, Lifestyle Factors And Age At Natural Menopause: A Systematic Review And Meta Analysis Of Study Accros Six Continent. International Journal of epidemiology.

Shuster, Lynne T dkk. (2011). Premature Menopause or Early Menopause: Long-Term Health Consequences. Maturitas. Feb 2011; 65(2): 161

Speroff L \& Reits, M. (2010). Clinical Gynecologic Endocrinology and infertility. Lippincott william \& Wilkins. USA.

Tehrani, Fahimeh R. (2014). Secular Trend Menopausal Age And Related Factors Among Tehrani Woman Born Form 1930 To 1960 : Tehran Lipid And Glucose Study, Arch Iran Med

Tomey, A. M., \& Alligood, M. R. (2011). Nursing Theorists And Their Work. $4^{\text {th }}$ ed. USA: Mosby-Year Book inc.

Tagliaferri, M., Cohen, I., \& Tripathy, D. (2006).. Ihwal Yang Perlu Anda Ketahui Tentang Menopause. Alih Bahasa. Jakarta: PT Indeks.

Washington, T.R. (2013) Older Adult Kidney Disease Self-Management Behaviors And Their Relationship To Deppresion, And Social Support. United State

Wilkinson, A., \& Whitehead, L. (2009). Evolution Of The Concept Of Self-Care And Implications For Nurses: A literature review. International Journal of Nursing Studies. 46, 1143-1147

World health organization global health observatory. (2014). Data Respository Life Expectancy. Data bycountry. http://apps.who.int/gho/data/node.main.668?lang=en diakses pada tanggal 6 Januari 2019

World Health Organization. (2016). Bulettin of the world health organization. Tersedia pada: http://www.who.int/publications/en/ diakses pada tanggal 6 Januari 2019 